\title{
Radiographic changes and clinical outcomes after open and closed wedge high tibial osteotomy: a systematic review and meta-analysis
}

Xiangyun Cheng, Fanxiao Liu* (D), Fei Xiong, Yijiang Huang and Alexander Christoph Paulus

\begin{abstract}
Background: The purpose of this meta-analysis is to examine changes in radiological variables and clinical outcomes between open and closed wedge high tibial osteotomy (OWHTO and CWHTO, respectively), which have ongoing controversial issues in numerous quantitative clinical studies.

Methods: PubMed, Embase, and the Cochrane Library were systematically searched for suitable controlled trials between Jan 1, 1999, and Feb 2, 2018. The inclusion criteria included studies written in English, studies with a level of evidence of I-IV, and studies presenting comparisons between OWHTO and CWHTO. The main clinical and radiographic results were extracted and pooled using Stata 12.0.

Results: After searching for and screening trials, 28 trials involving 2840 knees were eligible for the meta-analysis. After OWHTO or CWHTO, clinical scores, including the American Knee Society Score, Hospital for Special Surgery Knee Score, Lysholm score, and Visual Analog Scale pain score, improved $(p<0.05)$, but the range of motion was unchanged $(p>0.05)$. The anatomical femorotibial angle (SMD $0.04,95 \% \mathrm{Cl}-0.66$ to 0.74$)$ and hip-knee-ankle angle (SMD 0.11, 95\% Cl - 0.11 to 0.33) data suggested that the OWHTO and CWHTO groups were similar in function of correction. Posterior tibial slope increased (SMD $-0.71,95 \% \mathrm{Cl}-1.04$ to -0.37 ) after OWHTO but decreased (SMD $0.72,95 \%$ Cl 0.35 to 1.08) after CWHTO. OWHTO decreased patellar height $(p<0.05)$, while patellar height did not change significantly after CWHTO ( $p>0.05)$.

Conclusion: This meta-analysis indicates that compared with CWHTO, OWHTO increases the posterior slope, decreases the patellar height, and provides a similar accuracy of correction; however, CWHTO leads to a decreased posterior slope and an unchanged patellar height. Therefore, programs should be personalized and customized for the specific situation of each patient.
\end{abstract}

Keywords: CWHTO, OWHTO, Radiographic results, Clinical outcomes, Osteoarthritis

\section{Background}

The load distribution at the physiological tibiofemoral joint is usually inconsistent $[1,2]$ because the load of the medial compartment accounts for more than $60 \%$ of the joint load as a result of varus malalignment [3]. Therefore, the medial compartment is susceptible to lesions in the early stages of osteoarthritis, and this

\footnotetext{
*Correspondence: woshi631@126.com

Department of Orthopaedic Surgery, Physical Medicine and Rehabilitation, University Hospital of Munich (LMU), Campus Großhadern, Marchioninistrasse 23, 81377 Munich, Germany
}

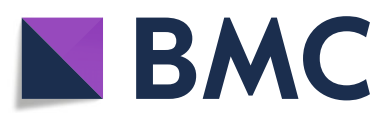

(c) The Author(s). 2019 Open Access This article is distributed under the terms of the Creative Commons Attribution 4.0 International License (http://creativecommons.org/licenses/by/4.0/), which permits unrestricted use, distribution, and reproduction in any medium, provided you give appropriate credit to the original author(s) and the source, provide a link to the Creative Commons license, and indicate if changes were made. The Creative Commons Public Domain Dedication waiver (http://creativecommons.org/publicdomain/zero/1.0/) applies to the data made available in this article, unless otherwise stated. [4].

High tibial osteotomy (HTO) is now considered effective surgical treatments for medial compartment arthritis $[5,6]$, which can maintain the integrity of the knee, reduce pain, and extend joint life, and HTO has been gaining attention in recent years [7]. The principle of high tibial osteotomy is to correct varus limb alignment so that the excessive pressure is transferred from the medial compartment to the relatively healthy lateral compartment.

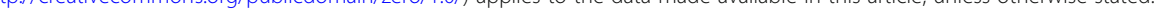


Medial open-wedge (OW) and lateral closed wedge (CW) HTO, during which a wedge-shaped cut is made in the medial and lateral parts of the tibia [8], respectively, and internal fixation with a plate and screws is then performed at the end $[2,9]$, are two of the most commonly used surgical methods among young and highly active patients.

To evaluate these two surgical methods, numerous studies have compared the radiographic changes and clinical results after OWHTO and CWHTO [6, 1014]. The choice of osteotomy site, anatomical femorotibial angle (AFTA), hip-knee-ankle angle (HKA), leg length, patellar height, posterior tibial slope, and correction accuracy are among the ongoing controversial issues [15-18]. As individual studies may not be able to provide sufficient data on their own, the effect of OWHTO and CWHTO should be assessed objectively using pooled analysis.

Although several meta-analyses $[14,19,20]$ were performed earlier, most evaluated only postoperative outcomes. A preoperative comparative analysis is also quite important, which could make results more persuasive and accurate. The posterior tibial slope (PTS) was measured by two different methods (measuring line: posterior tibial cortex or tibial mechanical axis) in some studies comparing OWHTO and CWHTO $[16,18,21-$ $24]$, but some meta-analyses $[14,19,20]$ pooled the results of different methods together, which may be not completely accurate. Additionally, numerous recently published studies [23-27] have longer follow-up times or present different directions for evaluating the effects of these two surgical methods. Therefore, regarding the current dilemma, the purpose of this meta-analysis is to examine changes in radiological variables and clinical outcomes between OWHTO and CWHTO which have ongoing controversial issues in numerous quantitative clinical studies and to assist surgeons in determining the appropriate method according to the patient condition. This study hypothesizes that OWHTO is better than CWHTO in clinical outcomes, that there are no differences in the function of correction between OWHTO and CWHTO, that posterior tibial slope increases after OWHTO and decreases after CWHTO, and that patellar height decreases after OWHTO and increases after CWHTO.

\section{Methods}

This meta-analysis was performed in strict accordance with the Preferred Reporting Items for Systematic Reviews and Meta-Analyses (PRISMA) Statement [28].

\section{Search strategy}

PubMed, Embase, and the Cochrane library were searched systematically, using English, to identify relevant studies published between Jan 1, 1999, and Feb 2, 2018. The complete search terms used in these three databases were tibial osteotomy [All Fields] AND high tibial osteotomy [All Fields] OR open wedge osteotomy [All Fields] OR open tibial osteotomy [All Fields] OR closed wedge high tibial osteotomy [All Fields] OR closed wedge osteotomy [All Fields] OR closed tibial osteotomy [All Fields]. Additionally, manual searches utilizing the reference lists of in included studies were performed to obtain articles neglected by searching the databases as mentioned above.

\section{Assessment of study eligibility}

The research question and eligibility criteria were determined a priori. The inclusion criteria were (1) studies presenting a comparison of results between OWHTO and CWHTO, (2) studies presenting at least one result for radiographic and clinical outcomes, and (3) clinical studies written in English and with a level of evidence of I-IV. Postoperative indicators less than 1 year of follow-up were divided into subgroups for analysis to reduce heterogeneity. For multiple articles containing the same sample population, the one with the relatively larger sample size or longer follow-up time was included in our investigation, and the others were used as a reference.

The exclusion criteria were (1) studies such as case reports, book chapters, review articles, summaries of experience, and cadaver studies; (2) animal or cell studies; (3) studies involving participations who had rheumatoid arthritis or former infection in the knee; and (4) studies presenting data from original articles that cannot be expressed as the mean \pm standard deviation.

\section{Data extraction}

The following information was extracted from each study: the first author's surname; publication year; country of origin; participant characteristics (number, age, and gender); operated knees; trial duration; type of internal fixation; clinical outcomes, including range of motion (ROM), Hospital for Special Surgery knee score (HSS), American Knee Society Score (KSS), Visual Analog Scale pain score (VAS), Lysholm score and the total of the Western Ontario and McMaster University osteoarthritis (WOMAC) index; and radiographic results, including anatomical femorotibial angle (AFTA), hip-knee-ankle angle (HKA), mechanical axis deviation (MAD), mechanical medial proximal tibia angle (MMPTA), posterior tibial slope angle (PTSA), Caton-Deschamps index (CDI), Insall-Salvati Index (ISI), and Blackburne-Peel index (BPI). All processes of data extraction were performed by two reviewers (Xiangyun Cheng \& Fanxiao Liu) repeatedly. 
Any discrepancies reached a consensus by discussion with an arbitrator (Fei Xiong).

\section{Quality assessment}

Quality assessment was performed for each included study using the "assessing risk of bias" table [29] for randomized controlled trial (RCT) studies and using the MINORS (Methodological Index for Nonrandomized Studies) checklist for nRCT articles. Discrepancies were resolved through discussion among the researchers (Xiangyun Cheng, Fanxiao Liu and Fei Xiong). Additionally, the quality of evidence for radiographic results and clinical outcomes was evaluated using the Grading of Recommendations Assessment, Development, and Evaluation (GRADE) approach [20].

\section{Statistical analysis}

For data measurement, the standardized mean difference (SMD) with a 95\% confidence interval (CI) was pooled using Stata 12.0 (Stata Corp, College Station, TX, USA). According to the Cochrane Handbook, statistical homogeneity, clinical homogeneity, and methodological homogeneity were evaluating using $I^{2}[28,29]$. If $p>0.1$ and, $I^{2}$ $<50 \%$, considering the heterogeneity is small, a fixed effects model was performed. Otherwise, the causes of heterogeneity were investigated using subgroup analysis and sensitivity analysis [14]. If the cause could not be identified, a random effects model was used. Subgroup analyses were performed based on the preoperative and postoperative results of the two groups (OWHTO and CWHTO), the data from RCTs and nRCTs, follow-up (more than 1 year). Kappa values were used to evaluate the degree of agreement between the two authors as follows: fair 0.40 to 0.59 , good 0.60 to 0.79 , and excellent 0.8 or more [29].

\section{Results}

Results of the search and study selection

After screening the titles and abstracts, 2708 of 2759 records (2748 retrieved from the 3 databases and 11 identified from references) were excluded. Subsequently, after downloading and identifying the full text, 3 articles with unavailable data, 8 duplicates, 3 cadaver studies, and 3 reviews were excluded (Fig. 1). Eventually, 28 articles [10-13, 15-18, 21-27, 30-42] published between 1999 and 2018 met the inclusion criteria and were included in the meta-analysis.

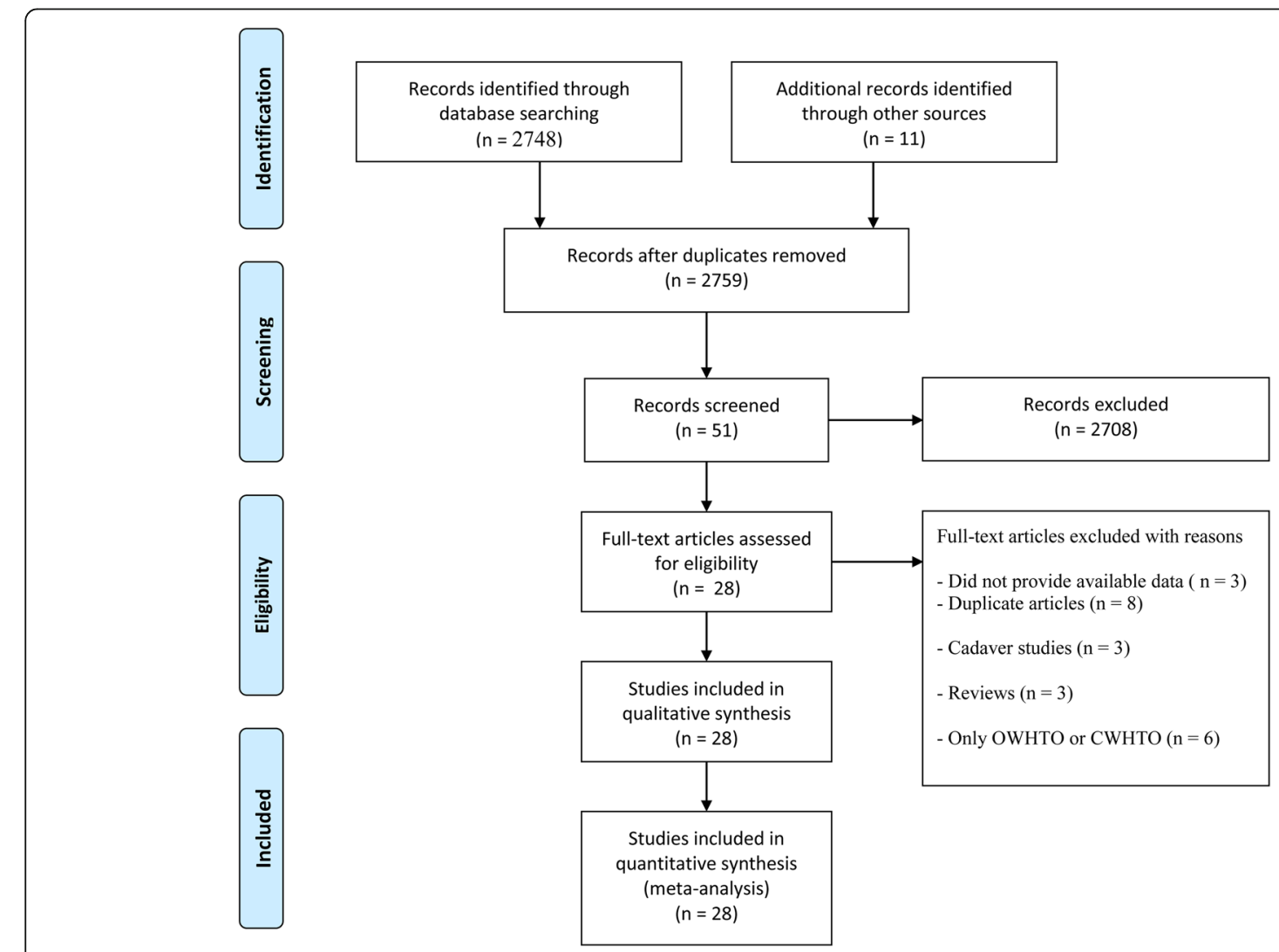

Fig. 1 Flow diagram of included and excluded studies 
Table 1 The main information of the included RCT and prospective studies

\begin{tabular}{|c|c|c|c|c|c|c|c|c|c|c|c|c|c|}
\hline Author & Year & Country & $\begin{array}{l}\text { Study } \\
\text { design }\end{array}$ & Surgery & Person & M & F & Knee & $\begin{array}{l}\text { Age mean } \pm \\
\text { SD (range) }\end{array}$ & Fixation type & BMI & $\begin{array}{l}\text { Time } \\
\text { range }\end{array}$ & $\begin{array}{l}\text { Follow- } \\
\text { up (year) }\end{array}$ \\
\hline \multirow[t]{2}{*}{ Polat } & 2017 & Turkey & $\mathrm{R}$ & C & 29 & NA & NA & 29 & $45.5 \pm 5.1$ & Puddu plate & NA & 1990-2010 & $\begin{array}{l}13.9 \pm \\
6.2\end{array}$ \\
\hline & & & & $\mathrm{O}$ & 88 & NA & NA & 88 & $44.6 \pm 7.4$ & Staples & NA & 1990-2010 & $\begin{array}{l}11.7 \pm \\
5.4\end{array}$ \\
\hline \multirow[t]{2}{*}{ Kim } & 2016 & Korea & $\mathrm{RCT}$ & C & 30 & 10 & 20 & 30 & $54.1 \pm 4$ & Stepped plate & $\begin{array}{l}25.7 \pm \\
3.4\end{array}$ & $\begin{array}{l}03.2013- \\
05.2015\end{array}$ & 1 \\
\hline & & & & $\mathrm{O}$ & 30 & 9 & 21 & 30 & $54.3 \pm 3.8$ & TomoFix plate & $\begin{array}{l}24.4 \pm \\
3.2\end{array}$ & $\begin{array}{l}03.2013- \\
05.2016\end{array}$ & 1 \\
\hline \multirow[t]{2}{*}{ Nerhus } & 2015 & Norway & $\mathrm{RCT}$ & C & 35 & NA & NA & 35 & $30-60$ & Two staples & NA & 2007-2013 & 0.5 \\
\hline & & & & $\mathrm{O}$ & 35 & NA & NA & 35 & $30-60$ & Puddu plate & NA & 2007-2014 & 0.5 \\
\hline \multirow[t]{2}{*}{ Duivenvoorden } & 2015 & Netherlands & $\mathrm{R}$ & C & 354 & 203 & 151 & 354 & $49.4 \pm 9$ & $\begin{array}{l}\text { TomoFix plate/ } \\
\text { Puddu plate }\end{array}$ & $\begin{array}{l}29.5 \pm \\
5.8\end{array}$ & 1993-2012 & $\begin{array}{l}10.6 \pm \\
5.1\end{array}$ \\
\hline & & & & $\mathrm{O}$ & 112 & 72 & 39 & 112 & $48.7 \pm 10.1$ & $\begin{array}{l}\text { TomoFix plate/ } \\
\text { Puddu plate }\end{array}$ & $\begin{array}{l}28.5 \pm \\
4.5\end{array}$ & 1993-2012 & $7.4 \pm 3.2$ \\
\hline \multirow[t]{2}{*}{ Portner } & 2014 & Canada & $\mathrm{R}$ & C & 18 & 15 & 3 & 18 & $\begin{array}{l}46.5 \pm 5.17 \\
(36-54)\end{array}$ & Two staples & NA & 2006-2012 & 05 \\
\hline & & & & $\mathrm{O}$ & 26 & 20 & 6 & 26 & $\begin{array}{l}43.9 \pm 8.48 \\
(21-59)\end{array}$ & Plate and screws & NA & $2007-2010$ & 0.5 \\
\hline \multirow[t]{2}{*}{ Hanada } & 2014 & Japan & $\mathrm{R}$ & C & 20 & 6 & 14 & 16 & $63.2(30-78)$ & NA & NA & $\begin{array}{l}09.2005- \\
01.2007\end{array}$ & 1 \\
\hline & & & & $\mathrm{O}$ & & & & 10 & $63.2(30-78)$ & NA & NA & 2007-2009 & 1 \\
\hline \multirow[t]{2}{*}{ Egmond } & 2014 & Netherlands & $\mathrm{RCT}$ & C & 25 & 16 & 9 & 25 & $50.3 \pm 7.4$ & $\begin{array}{l}\text { Four-hole angle } \\
\text { stable plate }\end{array}$ & $\begin{array}{l}28.4 \pm \\
3.0\end{array}$ & 2002-2013 & 7.9 \\
\hline & & & & $\mathrm{O}$ & 25 & 15 & 10 & 25 & $47.1 \pm 8.5$ & Phosphate plate & $\begin{array}{l}29.7 \pm \\
4.2\end{array}$ & $2002-2013$ & 7.9 \\
\hline \multirow[t]{2}{*}{$\begin{array}{l}\text { Duivenvoorden- } \\
2\end{array}$} & 2014 & Netherlands & RCT & C & 45 & 27 & 18 & 45 & $49.5 \pm 9.2$ & Staples & $\begin{array}{l}28.2 \pm \\
4.9\end{array}$ & $\begin{array}{l}01.2001- \\
04.2004\end{array}$ & 6 \\
\hline & & & & $\mathrm{O}$ & 36 & 24 & 12 & 36 & $49.9 \pm 7.9$ & Puddu plates & $\begin{array}{l}27.3 \pm \\
5.4\end{array}$ & $\begin{array}{l}01.2001- \\
04.2005\end{array}$ & 6 \\
\hline \multirow[t]{2}{*}{ Deie } & 2014 & Japan & $\mathrm{R}$ & C & 12 & 3 & 9 & 12 & $57.8 \pm 6.0$ & Plate fixation & $\begin{array}{l}24.8 \pm \\
3.3\end{array}$ & $2011-2012$ & 1 \\
\hline & & & & $\mathrm{O}$ & 9 & 3 & 6 & 9 & $57.5 \pm 6.0$ & Plate fixation & $\begin{array}{l}28.2 \pm \\
4.0\end{array}$ & 2011-2012 & 1 \\
\hline \multirow[t]{2}{*}{ Tabrizi } & 2013 & Iran & $\mathrm{R}$ & C & 16 & 12 & 4 & 21 & $35.1 \pm 9.7$ & LorT-plate & NA & NA & 0.5 \\
\hline & & & & $\mathrm{O}$ & 16 & 13 & 3 & 21 & $36.5 \pm 8.1$ & One plate & NA & NA & 0.5 \\
\hline \multirow[t]{2}{*}{ Soleimanpour } & 2013 & Iran & $\mathrm{R}$ & $C$ & 16 & 12 & 4 & 21 & $35.1 \pm 9.7$ & LorT-plate & NA & NA & 0.5 \\
\hline & & & & $\mathrm{O}$ & 16 & 13 & 3 & 21 & $36.5 \pm 8.1$ & Plate & NA & NA & 0.5 \\
\hline \multirow[t]{2}{*}{ Bae } & 2013 & Korea & $P$ & $C$ & 74 & 4 & 70 & 78 & $58.75 \pm 7.5$ & Mini-plate-staple & $25 \pm 2.5$ & $\begin{array}{l}04.2005- \\
01.2007\end{array}$ & 3.4 \\
\hline & & & & $\mathrm{O}$ & 28 & 2 & 25 & 30 & $56.3 \pm 7.5$ & Puddu plate & $\begin{array}{l}25.1 \pm \\
2.7\end{array}$ & $\begin{array}{l}04.2005- \\
01.2007\end{array}$ & 3.4 \\
\hline \multirow[t]{2}{*}{ Filho } & 2013 & Germany & $P$ & C & 117 & 60 & 57 & 117 & $54.5 \pm 9.7$ & NA & $\begin{array}{l}27.8 \pm \\
5.1\end{array}$ & NA & $\begin{array}{l}13.2 \pm \\
6.2\end{array}$ \\
\hline & & & & $\mathrm{O}$ & 24 & 16 & 8 & 24 & $57.3 \pm 7.0$ & NA & $\begin{array}{l}29.4 \pm \\
5.2\end{array}$ & NA & $7.4 \pm 4.7$ \\
\hline \multirow[t]{2}{*}{ Amzallag } & 2013 & Germany & $P$ & C & 97 & 205 & 116 & 97 & $49.7 \pm 10.30$ & NA & $27 \pm 4.4$ & $\begin{array}{l}01.2008- \\
03.2009\end{array}$ & 0.5 \\
\hline & & & & $\mathrm{O}$ & 224 & & & 224 & $53.6 \pm 8.6$ & NA & $28 \pm 5$ & $\begin{array}{l}01.2008- \\
03.2009\end{array}$ & 0.5 \\
\hline Song & 2012 & Korea & $\mathrm{R}$ & C & 50 & 12 & 38 & 50 & $60.1(46-65)$ & Two staples & NA & $\begin{array}{l}01.1996- \\
03.2006\end{array}$ & 3.6 \\
\hline
\end{tabular}


Table 1 The main information of the included RCT and prospective studies (Continued)

\begin{tabular}{|c|c|c|c|c|c|c|c|c|c|c|c|c|c|}
\hline Author & Year & Country & $\begin{array}{l}\text { Study } \\
\text { design }\end{array}$ & Surgery & Person & M & $\mathrm{F}$ & Knee & $\begin{array}{l}\text { Age mean } \pm \\
\text { SD (range) }\end{array}$ & Fixation type & BMl & $\begin{array}{l}\text { Time } \\
\text { range }\end{array}$ & $\begin{array}{l}\text { Follow- } \\
\text { up (year) }\end{array}$ \\
\hline & & & & $\mathrm{O}$ & 50 & 10 & 40 & 50 & $57.9(49-65)$ & Plates & NA & $\begin{array}{l}01.1996- \\
03.2006\end{array}$ & 3.4 \\
\hline \multirow[t]{2}{*}{ Ducat } & 2012 & France & $P$ & $C$ & 97 & 205 & 116 & 92 & $52 \pm 9$ & NA & $\begin{array}{l}27.0 \pm \\
4.4\end{array}$ & $\begin{array}{l}01.2008- \\
03.2009\end{array}$ & 0.5 \\
\hline & & & & $\mathrm{O}$ & 224 & & & 210 & $49.7 \pm 10.3$ & NA & $\begin{array}{l}28.6 \pm \\
5.5\end{array}$ & $\begin{array}{l}01.2008- \\
03.2009\end{array}$ & 0.5 \\
\hline \multirow[t]{2}{*}{ Magnussen } & 2011 & France & $\mathrm{R}$ & C & 30 & 21 & 9 & 30 & $59(45-72)$ & $\begin{array}{l}\text { Blade and } \\
\text { screws }\end{array}$ & NA & $\begin{array}{l}01.2006- \\
12.2009\end{array}$ & 1 \\
\hline & & & & $\mathrm{O}$ & 32 & 22 & 10 & 32 & $54(42-65)$ & TomoFix plate & NA & $\begin{array}{l}01.2006- \\
12.2009\end{array}$ & 1 \\
\hline \multirow[t]{2}{*}{ Hankemeier } & 2010 & Germany & $P$ & $C$ & 26 & 42 & 19 & 26 & $53(27-74)$ & $\begin{array}{l}\text { Screw-plate } \\
\text { fixation }\end{array}$ & NA & $\begin{array}{l}01.2001- \\
12.2005\end{array}$ & 2.2 \\
\hline & & & & $\mathrm{O}$ & 35 & & & 35 & $44(18-68)$ & TomoFix plate & NA & $\begin{array}{l}01.2001- \\
12.2005\end{array}$ & 2.2 \\
\hline \multirow[t]{2}{*}{ Gaasbeek } & 2010 & Netherlands & RCT & C & 25 & 16 & 9 & 25 & $48.4 \pm 8$ & $\begin{array}{l}\text { Four-hole locked } \\
\text { plate }\end{array}$ & $\begin{array}{l}28.4 \pm \\
2.9\end{array}$ & $\begin{array}{l}01.2003- \\
03.2005\end{array}$ & 1 \\
\hline & & & & $\mathrm{O}$ & 25 & 14 & 11 & 25 & $49.8 \pm 7.4$ & $\begin{array}{l}\text { Four-hole locked } \\
\text { plate }\end{array}$ & $\begin{array}{l}29.7 \pm \\
4.2\end{array}$ & $\begin{array}{l}01.2003- \\
03.2005\end{array}$ & 1 \\
\hline \multirow[t]{2}{*}{ El-Azab } & 2010 & Germany & $\mathrm{R}$ & C & 50 & 6 & 538 & 50 & $45.8 \pm 4$ & L-plate & NA & $\begin{array}{l}01.2000- \\
12.2006\end{array}$ & $0.7-1.25$ \\
\hline & & & & $\mathrm{O}$ & 50 & & & 50 & $44.6 \pm 5$ & TomoFix plate & NA & $\begin{array}{l}01.2000- \\
12.2006\end{array}$ & $0.7-1.25$ \\
\hline \multirow[t]{2}{*}{ Luites } & 2009 & Netherlands & $\mathrm{RCT}$ & $C$ & 19 & 27 & 15 & 19 & $53(40-68)$ & TomoFix plate & $<30$ & $\begin{array}{l}12.2001- \\
07.2004\end{array}$ & 2 \\
\hline & & & & $\mathrm{O}$ & 23 & & & 23 & $53(40-68)$ & TomoFix plate & $<30$ & $\begin{array}{l}12.2001- \\
07.2004\end{array}$ & 2 \\
\hline \multirow[t]{2}{*}{ Schaefer } & 2008 & Switzerland & $\mathrm{R}$ & C & 29 & 18 & 40 & 29 & $47(26-65)$ & Plate fixation & $\begin{array}{l}26.7(19- \\
32.9)\end{array}$ & 1996-2002 & 2 \\
\hline & & & & $\mathrm{O}$ & 29 & & & 29 & $46(26-64)$ & Puddu plate & $\begin{array}{l}26.5(18- \\
32.8)\end{array}$ & 1996-2002 & 2 \\
\hline \multirow[t]{2}{*}{ Raaij } & 2008 & Netherlands & $P$ & $C$ & 8 & NA & NA & 8 & $50 \pm 8.6$ & Two staples & NA & 2006 & 1 \\
\hline & & & & $\mathrm{O}$ & 28 & NA & NA & 28 & $50 \pm 8.1$ & Puddu plate & NA & 2006 & 1 \\
\hline \multirow[t]{2}{*}{ El-Azab } & 2008 & Germany & $\mathrm{R}$ & C & 50 & 79 & 31 & 60 & $45 \pm 5.7$ & L-plates & NA & $\begin{array}{l}01.2000- \\
12.2006\end{array}$ & 0.7 \\
\hline & & & & $\mathrm{O}$ & 60 & & & 60 & $47.2 \pm 3.6$ & Puddu plate & NA & $\begin{array}{l}01.2000- \\
12.2006\end{array}$ & 0.7 \\
\hline \multirow[t]{2}{*}{ Brower } & 2006 & Netherlands & $\mathrm{RCT}$ & C & 47 & 27 & 20 & 47 & $50.8(22-64)$ & Two staples & $\begin{array}{l}28(19- \\
47)\end{array}$ & $\begin{array}{l}01.2001- \\
04.2004\end{array}$ & 1 \\
\hline & & & & $\mathrm{O}$ & 45 & 32 & 13 & 45 & $49.6(21-67)$ & Puddu plate & $\begin{array}{l}28.2(21- \\
40)\end{array}$ & $\begin{array}{l}01.2001- \\
04.2004\end{array}$ & 1 \\
\hline \multirow[t]{2}{*}{ Hoell } & 2005 & Germany & R & $C$ & 51 & 32 & 19 & 51 & $52.1 \pm 8.4$ & Coventry staples & $29 \pm 4.2$ & 2001 & $0.8-3$ \\
\hline & & & & $\mathrm{O}$ & 40 & 28 & 12 & 40 & $46.4 \pm 8$ & Puddu plate & $30 \pm 5.2$ & 2001 & $0.8-3$ \\
\hline \multirow[t]{2}{*}{ Brouwer-2 } & 2005 & Netherlands & $\mathrm{RCT}$ & $C$ & 24 & 12 & 12 & 24 & $47.7 \pm 7.4$ & Two staples & NA & $\begin{array}{l}01.2001- \\
01.2003\end{array}$ & 1 \\
\hline & & & & $\mathrm{O}$ & 26 & 20 & 6 & 26 & $50.1 \pm 8.2$ & Puddu plate & NA & $\begin{array}{l}01.2001- \\
01.2003\end{array}$ & 1 \\
\hline \multirow[t]{2}{*}{ Tigani } & 2001 & Italy & $\mathrm{R}$ & $C$ & 44 & 22 & 22 & 47 & $59.1 \pm 15$ & Coventry staples & NA & NA & 3.6 \\
\hline & & & & $\mathrm{O}$ & 34 & 12 & 24 & 40 & $63.1 \pm 7$ & Plaster cast & NA & NA & 3.6 \\
\hline
\end{tabular}




\section{Basic characteristics of included studies}

The basic information of the included studies is summarized in Table 1. Of these articles, eight articles [10, 11, $13,24,26,27,30,31]$ were randomized controlled trials (RCTs) and 20 articles [12, 15-18, 21-23, 25, 32-42] were nRCTs. Two studies [27, 30] used the WOMAC score, and only one study used the Lysholm score [13]. The duration of follow-up in these studies ranged from 6 months to 13 years. These studies included a total of 2788 participants (1370 in OWHTO and 1438 in CWHTO) involving 2840 knees (1384 in OWHTO and 1456 in CWHTO).

\section{Risk of bias}

The risk of bias, which is used to assess RCTs, is presented in Fig. 2. The MINORS score assessing nRCTs was $15 \pm 2$, and their levels of evidence were III or

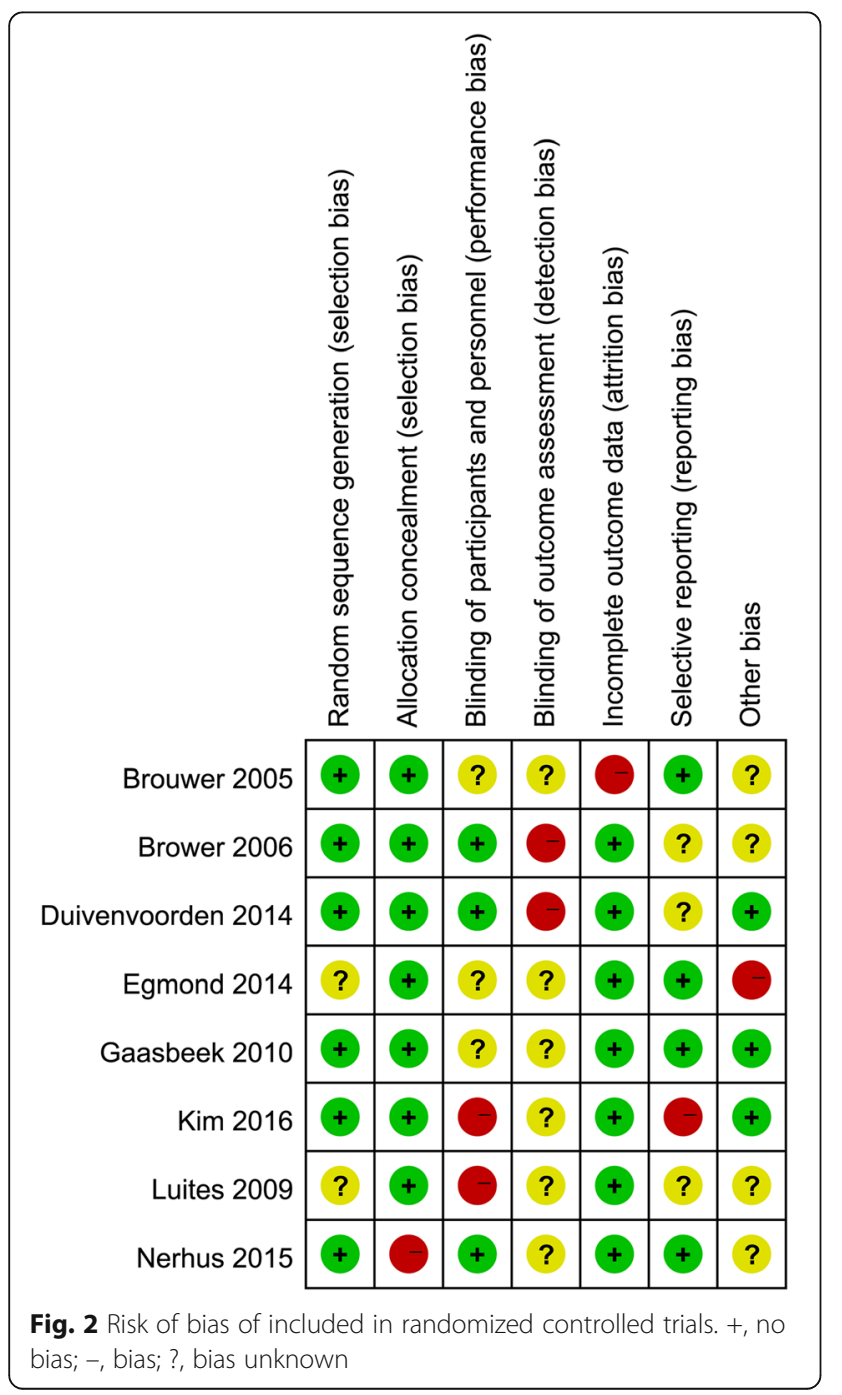

IV (Table 2). The kappa values regarding the evaluation of the risk of bias in RCTs and nRCTs were 0.821 and 0.803 , respectively, indicating the excellent degree of agreement between the two researchers (Xiangyun Cheng \& Fanxiao Liu).

\section{Clinical outcomes}

Preoperative HSS, VAS, and KSS were not statistically significant between the OWHTO and CWHTO groups $(p>0.05)$. Similarly, postoperative comparisons of the two groups showed no statistically significant differences $(p>0.05)$. However, for these three indicators, the postoperative scores were significantly better than the preoperative scores. The postoperative ROM difference between the two groups was not statistically significant $(p>0.05)$. OWHTO increased the length of the leg, while CWHTO decreased the condition $(p<0.05)$.

\section{Radiological outcomes}

Comparison of the AFTA between the CWHTO and OWHTO groups showed no statistically significant difference $(p>0.05)$ either at preoperation (SMD $0.04,95 \%$ CI -0.66 to 0.74 ) or postoperation (SMD $0.08,95 \%$ CI -0.23 to -0.37 ) (Table 3). However, the postoperation AFTA was better than the preoperation AFTA $(p<0.05)$ for both the CWHTO and OWHTO groups, which demonstrated that the OWHTO and CWHTO surgeries were similar in function of correction. Furthermore, similar results of the H-K-A angle between the two methods were found (Table 4).

For PTS, whether using the posterior tibial cortex or the tibia mechanical axis as a reference line, there were significant differences $(p<0.05)$ between the CWHTO and OWHTO groups at postoperation. Meanwhile, the PTS increased (SMD - 0.71, 95\% CI - 1.04 to $-0.37, p<0.05)$ after OWHTO but decreased significantly after CWHTO (SMD 0.72, 95\% CI 0.35 to $1.08, p<0.05$ ) (Figs. 3 and 4 ).

The patellar height, as evaluated by three indicators (BPI, CDI, and ISI), decreased significantly after OWHTO $(p<0.05)$, except for one subgroup of nRCTs in ISI (Table 3 and Table 4). However, the patellar height after CWHTO demonstrated no significant difference between postoperation and preoperation $(p>0.05)$.

All results of the preoperative comparison and postoperative comparison in the two groups are presented in Table 3. The comparison of preoperative and postoperative outcomes of each group is shown in Table 4. Considering that some included articles 
Table 2 The MINORS score of the relevant studies (NRCT)

\begin{tabular}{|c|c|c|c|c|c|c|c|}
\hline Author & Year & Country & Study design & No. of groups & LoE & MINORS score & Follow-up (year) \\
\hline Polat & 2017 & Turkey & Retrospective & $2(\mathrm{OW} / \mathrm{CW})$ & 3 & 13 & $12.4 \pm 6.2$ \\
\hline Duivenvoorden & 2015 & Netherlands & Retrospective & $2(\mathrm{OW} / \mathrm{CW})$ & 3 & 13 & $10.6 \pm 5.1$ \\
\hline Portner & 2014 & Canada & Retrospective & 3(OW/CW/CO) & 3 & 14 & 0.5 \\
\hline Hanada & 2014 & Japan & Retrospective & $2(\mathrm{OW} / \mathrm{CW})$ & 4 & 12 & 1 \\
\hline Deie & 2014 & Japan & Retrospective & $2(\mathrm{OW} / \mathrm{CW})$ & 3 & 15 & 1 \\
\hline Tabrizi & 2013 & Iran & Retrospective & $2(\mathrm{OW} / \mathrm{CW})$ & 4 & 12 & 0.5 \\
\hline Soleimanpour & 2013 & Iran & Retrospective & $2(\mathrm{OW} / \mathrm{CW})$ & 4 & 12 & 0.5 \\
\hline Bae & 2013 & Korea & Prospective & $2(\mathrm{OW} / \mathrm{CW})$ & 3 & 17 & 3.4 \\
\hline Filho & 2013 & Germany & Prospective & $2(\mathrm{OW} / \mathrm{CW})$ & 3 & 15 & $13.2 \pm 6.2$ \\
\hline Amzallag & 2013 & Germany & Prospective & $2(\mathrm{OW} / \mathrm{CW})$ & 3 & 17 & 0.5 \\
\hline Song & 2012 & Korea & Retrospective & $2(\mathrm{OW} / \mathrm{CW})$ & 3 & 18 & 3.6 \\
\hline Ducat & 2012 & France & Prospective & $2(\mathrm{OW} / \mathrm{CW})$ & 3 & 14 & 0.5 \\
\hline Magnussen & 2011 & France & Retrospective & $2(\mathrm{OW} / \mathrm{CW})$ & 3 & 16 & 1 \\
\hline Hankemeier & 2010 & Germany & Prospective & $2(\mathrm{OW} / \mathrm{CW})$ & 3 & 15 & 2.2 \\
\hline El-Azab & 2010 & Germany & Retrospective & $2(\mathrm{OW} / \mathrm{CW})$ & 3 & 19 & $0.7-1.25$ \\
\hline Schaefer & 2008 & Switzerland & Retrospective & $2(\mathrm{OW} / \mathrm{CW})$ & 3 & 15 & 2 \\
\hline Raaij & 2008 & Netherlands & Prospective & $2(\mathrm{OW} / \mathrm{CW})$ & 3 & 15 & 1 \\
\hline El-Azab & 2008 & Germany & Retrospective & $2(\mathrm{OW} / \mathrm{CW})$ & 3 & 16 & 0.7 \\
\hline Hoell & 2005 & Germany & Retrospective & $2(\mathrm{OW} / \mathrm{CW})$ & 4 & 15 & $0.8-3$ \\
\hline Tigani & 2001 & Italy & Retrospective & $2(\mathrm{OW} / \mathrm{CW})$ & 3 & 18 & 3.6 \\
\hline
\end{tabular}

OWHTO open wedge high tibial osteotomy, CWHTO closed wedge high tibial osteotomy, CO combined osteotomy, nRCT non-randomized controlled trial, LOE level of evidence, MINORS methodological index for non-randomized controlled studies

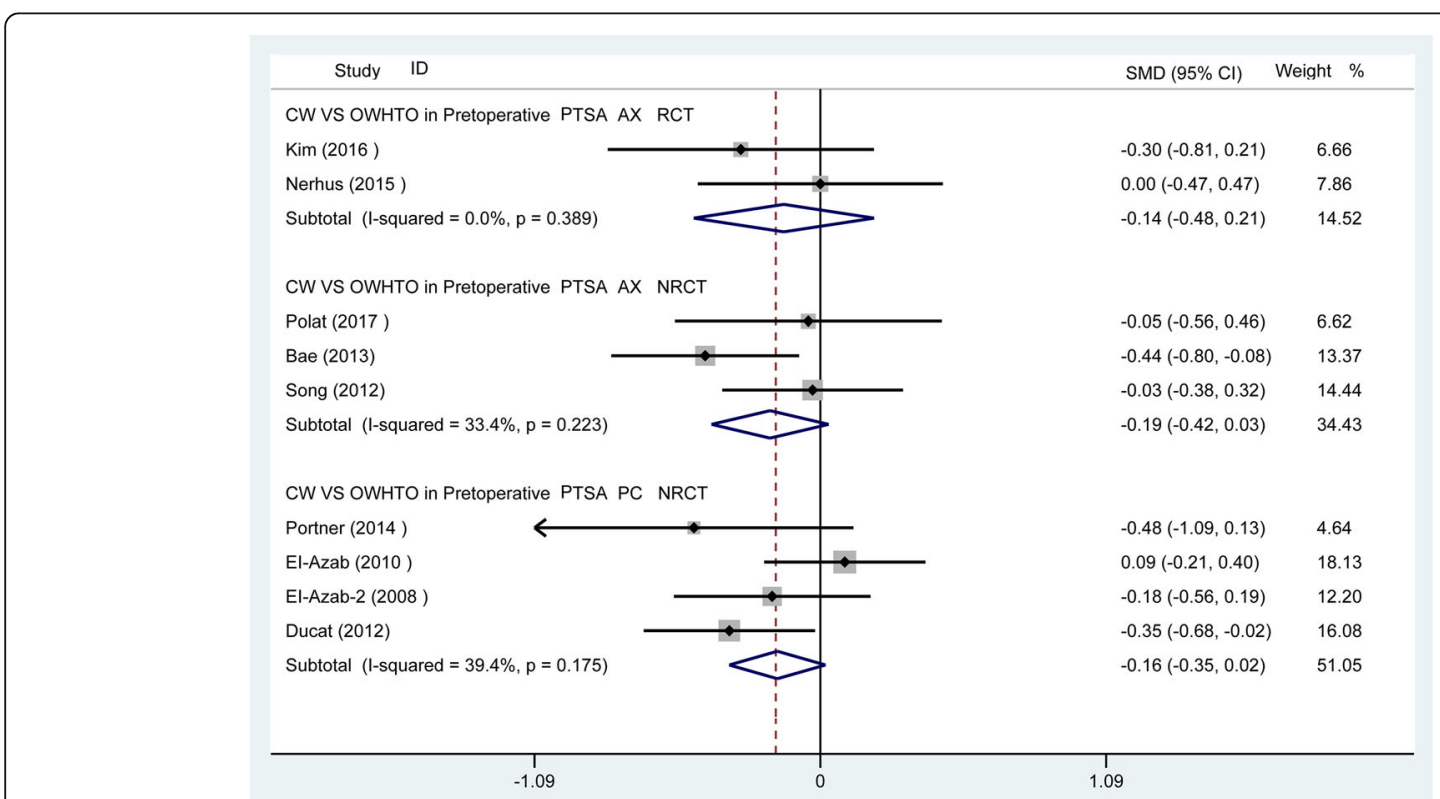

Fig. 3 Preoperative comparison between two groups for PTS 


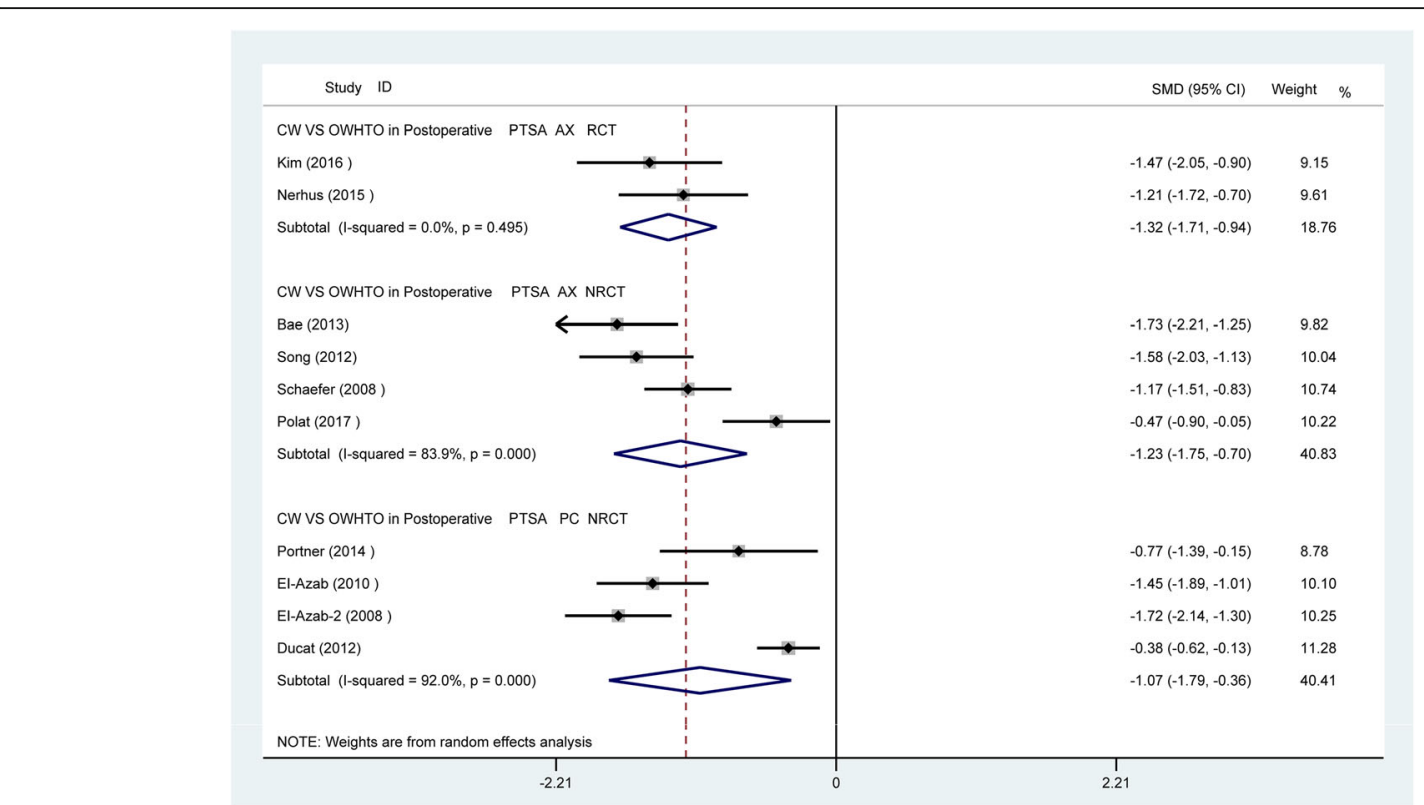

Fig. 4 Postoperative comparison between two groups for PTS

(follow-ups: less 1 year) may negatively skew the results, an analysis of subgroups of follow-ups more than 1 year was performed, and the results of subgroups were consistent with the overall results comparing postoperative outcomes of CWHTO and OWHTO (Table 5 and Table 6).

\section{Discussion}

This meta-analysis of 28 studies indicates that there are no differences $(p>0.05)$ in the function of correction (AFTA and HKA) and main clinical outcomes (HSS, KSS, and VAS) between OWHTO and CWHTO, that PTS increases after OWHTO but decreases after CWHTO $(p<0.05)$, and that patellar height (CDI, BPI, and ISI) decreases $(p<0.05)$ after OWHTO but does not change after CWHTO $(p>$ 0.05).

The medial compartment receives a greater load (approximately 60\%) in healthy knees than the lateral compartment $[43,44]$. If the tibia has some degree of varus deformity, the pressure on the cartilage in the medial compartment will significantly increase beyond the range of tolerance, triggering cartilage wear and inflammation and resulting in medial osteoarthritis [4, 45]. Historically, HTO was first reported by Jackson et al. [46] in the 1960s. The original intention of HTO was to correct tibial varus deformity to properly transfer some stress to the lateral compartment, significantly reducing the pressure in the medial compartment and effectively preventing cartilage wear and relieving pain symptoms. After 50 years of development, HTO has evolved into a much safer, more accurate and more effective surgical procedure for patients with medial compartmental arthritis [37].

Previously, a clinical study including 39 HTO cases [47] presented a reliable result with the survival rate of $82 \%$ at 12 -year follow-up. If seven patients with bicompartmental osteoarthritis receiving HTO were excluded in this study, it was foreseeable that these results would become better. Therefore, Berman et al. [47] emphasized that considerably strict indications and careful preoperative imaging assessments are critical for HTO. Currently, the best indications for HTO are relatively young, active patients with medial knee osteoarthritis or with a tibial varus greater than $5^{\circ}$ [47-49]. Emphatically, most cases included in this meta-analysis are in line with these indications for HTO.

To evaluate the controversial clinical effects between OWHTO and CWHTO, we compared the outcomes according to the included articles $[10,13,24$, $27,30,31]$. As the results imply, the postoperative results of VAS, HSS, KSS, Lytolom score, and WOMAC were better than the preoperative results in both groups $(p<0.05)$, which indicated that both surgical methods were effective. However, there was no significant difference comparing the postoperative results of CWHTO and OWHTO $(p>0.05)$. Additionally, it should be emphasized that no significant change was found in the range of motion after OWHTO or CWHTO $(p>0.05)$ in this study. Similarly, following up for a minimum of 3 years and 1 year 
Table 3 Radiological and clinical results of the preoperative comparison and postoperative comparison between OWHTO and CWHTO

\begin{tabular}{|c|c|c|c|c|c|c|}
\hline \multirow{2}{*}{$\begin{array}{l}\text { Categories and } \\
\text { comparison }\end{array}$} & \multirow[t]{2}{*}{ Studies } & \multicolumn{2}{|c|}{ Mean difference } & \multirow{2}{*}{$\begin{array}{l}P \\
\text { value }\end{array}$} & \multicolumn{2}{|c|}{ Heterogeneity } \\
\hline & & Mean & $(95 \% \mathrm{Cl})$ & & $\bar{P}(\%)$ & $p$ value \\
\hline \multicolumn{7}{|c|}{ CWHTO VS OWHTO in preoperative outcomes } \\
\hline \multicolumn{7}{|c|}{ Radiological outcomes RCT } \\
\hline HKA & $10,24,26,27,30$ & 0.11 & $(-0.11$ to 0.33$)$ & 0.33 & 0 & 0.792 \\
\hline MAD & 26 & 0 & $(-0.47$ to 0.47$)$ & 0.90 & NA & NA \\
\hline MMPTA & 26 & 0 & $(-0.46$ to 0.46$)$ & 0.95 & NA & NA \\
\hline PTSA (AX) & 24,26 & -0.14 & $(-0.48$ to 0.21$)$ & 0.38 & 0 & 0.39 \\
\hline $\mathrm{CDI}$ & 27,30 & 0.01 & $(-0.39$ to 0.37$)$ & 0.18 & 21 & 0.43 \\
\hline$|S|$ & 26,31 & 0.02 & $(-0.33$ to 0.38$)$ & 0.89 & 49 & 0.04 \\
\hline BPI & 31 & 0.49 & (0.05 to 1.06$)$ & 0.03 & NA & NA \\
\hline \multicolumn{7}{|c|}{ Radiological outcomes nRCT } \\
\hline HKA & $17,21,33,36,39,41$ & -0.08 & $(-0.28$ to 0.12$)$ & 0.44 & 0 & 0.85 \\
\hline MAD & 23 & 0.34 & $(-0.08$ to 0.74$)$ & 0.12 & NA & NA \\
\hline MMPTA & 23 & 0.06 & $(-0.36$ to 0.48$)$ & 0.79 & NA & NA \\
\hline PTSA (AX) & $16,21,23$ & -0.19 & $(-0.42$ to 0.03$)$ & 0.09 & 34.4 & 0.23 \\
\hline PTSA (PC) & $12,18,22,38$ & -0.16 & $(-0.35$ to 0.02$)$ & 0.08 & 39.4 & 0.18 \\
\hline $\mathrm{CDI}$ & $15,38,42$ & -0.01 & $(-0.21$ to 0.20$)$ & 0.95 & 94 & 0.001 \\
\hline$|S|$ & 22,38 & -0.20 & $(-0.53$ to 0.13$)$ & 0.23 & 0 & 0.43 \\
\hline $\mathrm{BPI}$ & $21,36,38$ & -0.22 & $(-0.50$ to 0.06$)$ & 0.13 & 0 & 0.37 \\
\hline AFTA & $22,33,40$ & 0.04 & $(-0.66$ to 0.74$)$ & 0.09 & 76.6 & 0.014 \\
\hline \multicolumn{7}{|l|}{ Clinical outcomes RCT } \\
\hline $\mathrm{ROM}$ & 24 & 0.08 & $(-0.42$ to 0.59$)$ & 0.75 & NA & NA \\
\hline HSS & $2,10,11$ & -0.04 & $(-0.294$ to 0.22$)$ & 0.78 & 0 & 0.92 \\
\hline KSS & 24 & 0.15 & $(-0.35$ to 0.66$)$ & 0.55 & NA & NA \\
\hline WOMAC & 27,30 & -0.32 & $(-0.72$ to 0.07$)$ & 0.12 & 0 & 0.99 \\
\hline VAS & $10,13,24,27,30,31$ & -0.11 & $(-0.32$ to 0.10$)$ & 0.23 & 4.2 & 0.39 \\
\hline \multicolumn{7}{|c|}{ Clinical outcomes nRCT } \\
\hline ROM & 21 & 0.28 & $(-0.62$ to 0.03$)$ & 0.08 & NA & NA \\
\hline HSS & 21,23 & -0.10 & $(-0.39$ to 0.19$)$ & 0.39 & 0 & 0.49 \\
\hline KSS & 23,36 & -0.05 & $(-0.35$ to 0.26$)$ & 0.76 & 0 & 0.47 \\
\hline Lysholm score & 13 & -0.34 & $(-0.95$ to 0.27$)$ & 0.28 & NA & NA \\
\hline \multicolumn{7}{|c|}{ CWHTO VS OWHTO in postoperative outcomes } \\
\hline \multicolumn{7}{|c|}{ Radiological outcomes RCT } \\
\hline HKA & $10,24,26,27,30$ & 0.21 & $(-0.01$ to 0.44$)$ & 0.06 & 0 & 0.83 \\
\hline HKA CORRECTION & $24,26,27$ & 0.16 & $(-0.13$ to 0.46$)$ & 0.28 & 0 & 0.65 \\
\hline MAD & 26 & 0.45 & $(-0.03$ to 0.92$)$ & 0.065 & NA & NA \\
\hline MMPTA & 26 & -2.76 & $(-3.42$ to -2.10$)$ & 0.001 & NA & NA \\
\hline PTSA (AX) & 24,26 & -1.32 & $(-1.71$ to -0.94$)$ & 0.001 & 0 & 0.495 \\
\hline CDI & 27,30 & 0.82 & (0.18 to 1.46$)$ & 0.012 & 59 & 0.547 \\
\hline$|S|$ & 26,31 & 0.46 & (0.09 to 0.82$)$ & 0.014 & 0 & 0.55 \\
\hline $\mathrm{BPI}$ & 31 & 0.49 & (0.05 to 1.06$)$ & 0.03 & NA & NA \\
\hline \multicolumn{7}{|c|}{ Radiological outcomes nRCT } \\
\hline HKA & $17,21,33,36,39,41$ & -0.04 & $(-0.24$ to 0.15$)$ & 0.67 & 0 & 0.71 \\
\hline
\end{tabular}


Table 3 Radiological and clinical results of the preoperative comparison and postoperative comparison between OWHTO and CWHTO (Continued)

\begin{tabular}{|c|c|c|c|c|c|c|}
\hline \multirow{2}{*}{$\begin{array}{l}\text { Categories and } \\
\text { comparison }\end{array}$} & \multirow[t]{2}{*}{ Studies } & \multicolumn{2}{|c|}{ Mean difference } & \multirow{2}{*}{$\begin{array}{l}P \\
\text { value }\end{array}$} & \multicolumn{2}{|c|}{ Heterogeneity } \\
\hline & & Mean & $(95 \% \mathrm{Cl})$ & & $\bar{P}(\%)$ & $p$ value \\
\hline HKA CORRECTION & 17 & 0.12 & $(-0.39$ to 0.63$)$ & 0.64 & NA & NA \\
\hline MAD & 23 & 0.32 & $(-0.11$ to 0.74$)$ & 0.14 & NA & NA \\
\hline MMPTA & 23 & -1.98 & $(-2.34$ to -1.62$)$ & 0.001 & NA & NA \\
\hline PTSA (AX) & $16,21,23$ & -1.19 & $(-1.40$ to -0.99$)$ & 0.001 & 83.9 & 0.001 \\
\hline PTSA (PC) & $12,18,22,38$ & -0.85 & $(-1.04$ to -0.67$)$ & 0.001 & 92 & 0.001 \\
\hline CDI & $15,38,42$ & 0.79 & (0.55 to 1.03$)$ & 0.001 & 30 & 0.24 \\
\hline$|S|$ & 22,38 & 0.06 & $(-0.27$ to 038$)$ & 0.74 & 0 & 0.99 \\
\hline BPI & $21,36,38$ & 0.33 & (0.04 to 0.70$)$ & 0.05 & 58.1 & 0.09 \\
\hline AFTA & $22,33,40$ & 0.08 & $(-0.23$ to 0.39$)$ & 0.46 & 12.2 & 0.32 \\
\hline \multicolumn{7}{|l|}{ Clinical outcomes RCT } \\
\hline VAS & $10,13,24,27,30,31$ & -0.11 & $(-0.31$ to 0.10$)$ & 0.30 & 33.8 & 0.18 \\
\hline ROM & 24 & -0.19 & $(-0.70$ to 0.32$)$ & 0.46 & NA & NA \\
\hline HSS & $10,24,31$ & 0.12 & $(-0.21$ to 0.45$)$ & 0.49 & 38.4 & 0.20 \\
\hline KSS & 24 & 0.41 & ( -0.01 to 0.93$)$ & 0.11 & NA & NA \\
\hline WOMAC & 27,30 & -0.42 & ( -0.12 to 0.18$)$ & 0.09 & 13 & 0.346 \\
\hline \multicolumn{7}{|l|}{ Clinical outcomes nRCT } \\
\hline Leg length change & 16,37 & -1.33 & $(-1.68$ to -0.97$)$ & 0.001 & 84.6 & 0.01 \\
\hline ROM & 43 & -0.36 & $(-0.66$ to 0.03$)$ & 0.06 & NA & NA \\
\hline HSS & 21,23 & -0.09 & $(-0.38$ to 0.20$)$ & 0.55 & 0 & 0.45 \\
\hline KSS & 23,31 & 0.09 & $(-0.22$ to 0.39$)$ & 0.58 & 0 & 0.52 \\
\hline Lysholm score & 13 & -0.38 & $(-0.99$ to 0.24$)$ & 0.23 & NA & NA \\
\hline
\end{tabular}

Postoperative results were compared between the two groups in the lower half of the table

AX Anatomical axia, $P C$ posterior cortex, $R C T$ randomized controlled trial, $n R C T$ non-randomized controlled trial, NA not available, ROM range of motion, HSS Hospital for Special Surgery Knee Score. KSS American Knee Society Score, VAS Visual Analog Scale Pain Score, WOMAC the total of Western Ontario and McMaster University Osteoarthritis Index, AFTA anatomical femorotibial angle, HKA hip-knee-ankle angle, MAD mechanical axis deviation, MMPTA mechanical medial proximal tibia angle, PTSA posterior tibial slope angle, CDI Caton-Deschamps Index, ISI Insall-Salvati Index, BPI Blackburne-Peel index

postoperatively, Song et al. [21] and Kim et al. [24] both found that mean maximal flexion was not significantly changed after OWHTO or CWHTO. Furthermore, when evaluating the influence of HTO technique on the performance and results of total knee arthroplasty (TKA) at a mean follow-up of 2 years, Filho et al. [36] indicated that post-TKA range of motion was not different between OWHTO and CWHTO.

Regarding the comparison of radiological results, the correction angle evaluated by H-K-A and AFTA (built between the mechanical axis and anatomical axis of the tibia and femur, respectively), is one of the most important indicators that can influence surgical outcomes [24]. In this study, postoperative H-K-A or AFTA did not show significant differences between OWHTO and CWHTO $(p>0.05)$, while the postoperation H-K-A or AFTA was better $(p<0.05)$ than the preoperation values in both groups, which demonstrated that the correction functions of OWHTO and CWHTO were similar. Three previous studies $[13,41,44]$ showed that both CWHTO and OWHTO could provide acceptable correction, which was consistent with our results. Considering the degree of correction, Aglietti et al. [50] indicated that the functional effect of surgery would be maintained at a follow-up of 10 years when keeping the valgus angle (AFTA) at 8 to $15^{\circ}$ after HTO. The significant undercorrection caused by the incompletely closed gap in CWHTO or the bone deficit in OWHTO could not reduce the medial tibial plateau load, leading to the loss of osteotomy angle and recurrence of varus. Additionally, overcorrection would cause an excessive lateral compartment load, accelerating degeneration of the articular cartilage [51, 52].

The original goal of HTO was to correct deformities of the coronal plane, but unexpected events, the changes in the PTS, occurring in the sagittal position are always inevitable [53, 54]. Our results showed that PTS increases after OWHTO $(p<0.05)$ and decreases 
Table 4 Radiological and clinical results comparing preoperative and postoperative outcomes in OWHTO or CWHTO group

\begin{tabular}{|c|c|c|c|c|c|}
\hline Categories & Studies & Mean & & & Heterogeneity \\
\hline $\begin{array}{l}\text { and } \\
\text { comparison }\end{array}$ & & $\overline{\text { Mean }}$ & $(95 \%$ Cl) & value & $\bar{P}(\%)$ \\
\hline
\end{tabular}

comparison

Preoperative VS postoperative results in CWHTO

Radiological outcomes RCT

$\begin{array}{lllllll}\text { HKA } & 10,24,26,27,30 & -3.17 & (-3.74 \text { to }-2.60) & 0.001 & 79 & 0.001 \\ \text { MAD } & 26 & -2.31 & (-2.92 \text { to }-1.70) & 0.001 & \text { NA } & \text { NA } \\ \text { MMPTA } & 26 & -2.90 & (-3.58 \text { to }-2.23) & 0.001 & \text { NA } \\ \text { PTSA (AX) } & 24,26 & 0.72 & (0.35 \text { to } 1.08) & 0.001 & 4.8 & 0.31 \\ \text { CDI } & 27,30 & -0.11 & (-0.50 \text { to } 0.29) & 0.59 & 0 & 0.59 \\ \text { ISI } & 26,31 & -0.10 & (-0.46 \text { to } 0.26) & 0.58 & 0 & 0.84 \\ \text { BPI } & 31 & -0.18 & (-0.75 \text { to } 0.39) & 0.53 & \text { NA }\end{array}$

Radiological outcomes nRCT

$\begin{array}{ll}\text { HKA } & 17,21,33,36,39,41 \\ \text { MAD } & 23 \\ \text { MMPTA } & 23 \\ \text { PTSA (AX) } & 16,21,23 \\ \text { PTSA (PC) } & 12,18,22,38 \\ \text { CDI } & 15,38,42 \\ \text { ISI } & 22,38 \\ \text { BPI } & 22,36,38 \\ \text { AFTA } & 22,33,40\end{array}$

$-2.75$

$-6.20$

$-1.54$

0.35

0.56

$-0.13$

$-0.03$

0.06

$-3.19$

Clinical outcomes RCT

VAS

$10,13,24,27,30,31$

ROM

24

HSS

$2,10,11$

KSS

24

WOMAC

27,30

Clinical outcomes nRCT

$\begin{array}{ll}\text { Lysholm } & 13 \\ \text { ROM } & 21 \\ \text { HSS } & 21,23 \\ \text { KSS } & 23,36\end{array}$

Preoperative VS postoperative results in OWHTO

Radiological outcomes RCT

$\begin{array}{ll}\text { HKA } & 10,24,26,27,30 \\ \text { MAD } & 26 \\ \text { MMPTA } & 26 \\ \text { PTSA (AX) } & 24,26 \\ \text { CDI } & 27,30 \\ \text { ISI } & 26,31 \\ \text { BPI } & 31\end{array}$

Radiological outcomes nRCT

$\begin{array}{ll}\text { HKA } & 17,21,33,36,39,41 \\ \text { MAD } & 23 \\ \text { MMPTA } & 23\end{array}$

$-2.78$

$-1.95$

$-2.76$

$-0.59$

0.65

0.28

0.58

$-2.84$

$-7.03$

$-1.98$
$(-3.77$ to -1.73$)$

$(-7.46$ to -4.95$)$

$(-2.13$ to -0.95$)$

(0.13 to 0.58 )

(0.20 to 0.92 )

(- 0.33 to 0.07$)$

$(-0.33$ to 0.28$)$

$(-0.22$ to 0.34$)$

$(-3.54$ to -2.69$)$

(1.05 to 2.27)

( -0.61 to 0.40 )

$(-1.34$ to -0.79$)$

$(-2.19$ to -1.02$)$

(1.19 to 2.11)

$(-2.16$ to -0.69$)$

(- 0.54 to 0.24$)$

(- 0.38 to 0.20$)$

( -2.72 to -0.63$)$

0.001

91.4

0.001

$(-2.52$ to -1.38$)$

0.001

$(-3.42$ to -2.10$)$

0.001

$(-0.94$ to -0.23$)$

0.001

0.002

(0.25 to 1.06)

0.04

0.04

(0.03 to 1.14 )

$(-3.14$ to -2.55$)$

0.001

$(-7.83$ to -6.24$)$

0.001

$(-2.35$ to -1.62$)$

0.001

$\begin{array}{ll}\text { NA } & \text { NA } \\ \text { NA } & \text { NA } \\ 0 & 0.45 \\ 90.6 & 0.52\end{array}$

NA

0.002

NA

0.14

NA

0.45

0.52

0.24

0.19

0.87

0.05

0.73

001

NA

NA

0.001

A

NA

03

$\begin{array}{lll}09 & 0 & 0.87\end{array}$

$\begin{array}{lll}0.69 .4 & 0.05 \\ 0.001 & 0 & 0.73\end{array}$

0.002

$\begin{array}{ll}91.4 & 0.001 \\ \text { NA } & \text { NA } \\ \text { NA } & \text { NA } \\ 0 & 0.68 \\ 0 & 0.45 \\ 0 & 0.34 \\ \text { NA } & \text { NA }\end{array}$

NA

NA

0.68

0.45

0.34

NA

0.001

$\begin{array}{ll}93.3 & 0.001 \\ \text { NA } & \text { NA } \\ \text { NA } & \text { NA }\end{array}$


Table 4 Radiological and clinical results comparing preoperative and postoperative outcomes in OWHTO or CWHTO group (Continued)

\begin{tabular}{|c|c|c|c|c|c|c|}
\hline \multirow{2}{*}{$\begin{array}{l}\text { Categories } \\
\text { and } \\
\text { comparison }\end{array}$} & \multirow[t]{2}{*}{ Studies } & \multicolumn{2}{|c|}{ Mean difference } & \multirow{2}{*}{$\begin{array}{l}p \\
\text { value }\end{array}$} & \multicolumn{2}{|c|}{ Heterogeneity } \\
\hline & & Mean & $(95 \% \mathrm{Cl})$ & & $P^{2}(\%)$ & $p$ value \\
\hline PTSA (AX) & $16,21,23$ & -0.71 & $(-1.04$ to -0.37$)$ & 0.001 & 69.5 & 0.02 \\
\hline PTSA (PC) & $12,18,22,38$ & -0.24 & $(-0.39$ to -0.09$)$ & 0.002 & 42.7 & 0.17 \\
\hline CDI & $15,38,42$ & 0.56 & (0.40 to 0.72 ) & 0.001 & 39.9 & 0.001 \\
\hline$|S|$ & 22,38 & 0.18 & $(-0.14$ to 0.50$)$ & 0.26 & 25.8 & 0.25 \\
\hline $\mathrm{BPI}$ & $21,36,38$ & 0.92 & (0.63 to 1.21$)$ & 0.001 & 29.6 & 0.23 \\
\hline AFTA & $22,33,40$ & -3.04 & $(-3.41$ to -2.67$)$ & 0.001 & 39 & 0.19 \\
\hline \multicolumn{7}{|c|}{ Clinical outcomes RCT } \\
\hline VAS & $10,13,24,27,30,31$ & 1.65 & (1.03 to 2.26$)$ & 0.001 & 84.6 & 0.001 \\
\hline $\mathrm{ROM}$ & 24 & -0.35 & $(-0.86$ to 0.17$)$ & 0.18 & NA & NA \\
\hline HSS & $10,24,31$ & -1.52 & $(-2.16$ to -0.88$)$ & 0.009 & 89.6 & 0.001 \\
\hline KSS & 24 & -2.14 & $(-2.78$ to -1.50$)$ & 0.001 & NA & NA \\
\hline WOMAC & 27,30 & 1.22 & (0.69 to 1.55$)$ & 0.001 & 80.5 & 0.02 \\
\hline \multicolumn{7}{|c|}{ Clinical outcomes nRCT } \\
\hline Lysholm & 13 & -1.53 & $(-2.19$ to -0.87$)$ & 0.001 & NA & NA \\
\hline $\mathrm{ROM}$ & 43 & -0.16 & $(-0.51$ to 0.28$)$ & 0.57 & NA & NA \\
\hline HSS & 21,23 & -1.72 & $(-2.38$ to -1.06$)$ & 0.001 & 80 & 0.001 \\
\hline KSS & 23,31 & -1.52 & $(-2.52$ to -0.52$)$ & 0.003 & 85.1 & 0.01 \\
\hline
\end{tabular}

AX Anatomical axia, $P C$ posterior cortex, $R C T$ randomized controlled trial, $n R C T$ non-randomized controlled trial, NA not available, $R O M$ range of motion, HSS Hospital for Special Surgery Knee Score, KSS American Knee Society Score, VAS Visual Analog Scale Pain Score, WOMAC the total of Western Ontario and McMaster University Osteoarthritis Index, AFTA anatomical femorotibial angle, HKA hip-knee-ankle angle, MAD mechanical axis deviation, MMPTA mechanical medial proximal tibia angle, PTSA posterior tibial slope angle, CDI Caton-Deschamps Index, ISI Insall-Salvati Index, BPI Blackburne-Peel index

$(p>0.05)$ after CWHTO, which is consistent with several comparative studies $[16,18,23,24,26]$. Multiple biomechanical and clinical studies attempted to identify the reasons for changes in PTS after HTO [33, 40, 44, 55]. First, surgeons cannot release the posterior soft tissues sufficiently [12], considering to protect muscles and posterior vessels [16, 22]. The other reason is that the triangular shape of the proximal tibia with the apex directed anteriorly makes the center of rotation angulation slightly posterior in the sagittal plane $[8,37,56]$. The demonstrations above cause a less opened posterior gap after OWHTO and a less touched area of the posterior bone after CWHTO.

Flexion and extension activities can be affected by unintended alterations of PTS in the sagittal plane $[44,55]$. Second, a linear relationship between tibial slope and tibial translation during unilateral weightbearing was shown: the greater the angle of slope was, the greater the anterior translation in knees was $[12,55]$; therefore, an increased anterior tibial translation after OWHTO can aggravate the load of the anterior cruciate ligament (ACL) [43].

To avoid the undesirable results caused by PTS, many researchers and clinicians have proposed many novel surgical techniques. Nerhus et al. [26] pointed out that PTS after OWHTO increased by a small amount or did not increase at all if the fixation plate was placed close to the posteromedial corner. The osteotomy height and the opening gap at the posteromedial cortex should be higher and broader than those at the tibial tuberosity, which can reduce or avoid changes of PTS pointed out by Giffin et al. [55]. Careful preoperative planning is also quite essential for reducing or preventing changes of PTS in HTOs [26, 38].

Three indicators (BPI, CDI, and ISI) were used to evaluate changes in the patella height. OWHTO reduced the patella height $(p<0.05)$, while statistically significant effects on the patellar height were not found after CWHTO $(p>0.05)$. Using the measurement of CDI, some researchers reported that patellar height decreases by 9 to $16 \%$ after OWHTO compared with that before surgery $[15,27,30,42]$, which was similar to our results. However, consistent with our pooled results, Song et al. [21] indicated that patellar height remained unchanged after CWHTO.

The reason for patellar decreasing after OWHTO is that the opening wedge of the medial tibia prolongs the proximal tibia, resulting in a reduction in the 
Table 5 Radiological results of the preoperative comparison and postoperative comparison between OWHTO and CWHTO after excluding the results of the follow-up within 1 year

\begin{tabular}{|c|c|c|c|c|c|}
\hline \multirow{2}{*}{$\begin{array}{l}\text { Categories and } \\
\text { comparison }\end{array}$} & \multirow[t]{2}{*}{ Studies } & \multicolumn{2}{|c|}{ Mean difference } & \multirow{2}{*}{$\begin{array}{l}P \\
\text { value }\end{array}$} & Heterogeneity \\
\hline & & $\overline{\text { Mean }}$ & $(95 \% \mathrm{Cl})$ & & $P(\%)$ \\
\hline
\end{tabular}

CWHTO VS OWHTO in preoperative outcomes

Radiological outcomes RCT

$\begin{array}{lllllll}\text { HKA } & 10,24,27,30 & 0.14 & (-0.11 \text { to } 0.39) & 0.266 & 0 & 0.703 \\ \text { PTSA (AX) } & 24 & -0.30 & (-0.81 \text { to } 0.21) & 0.242 & \text { NA } & \text { NA } \\ \text { ISI } & 31 & 0.06 & (-0.49 \text { to } 0.61) & 0.84 & \text { NA } & \text { NA }\end{array}$

Radiological outcomes nRCT

$\begin{array}{llllll}\text { PTSA (PC) } & 12 & -0.18 & (-0.54 \text { to } 0.17) & 0.314 & \text { NA } \\ \text { CDI } & 42 & -0.25 & (-0.67 \text { to } 0.17) & 0.24 & \text { NA }\end{array}$

CWHTO VS OWHTO in postoperative outcomes

Radiological outcomes RCT

\begin{tabular}{lllllll} 
HKA & $10,24,27,30$ & 0.249 & $(-0.01$ to 0.503$)$ & 0.06 & 0 & 0.769 \\
HKA CORRECTION & 24,27 & 0.15 & $(-0.21$ to 0.63$)$ & 0.40 & 0.35 \\
PTSA (AX) & 24 & -1.47 & $(-2.04$ to -0.90$)$ & 0.001 & NA & NA \\
ISI & 31 & 0.59 & $(0.02$ to 1.15$)$ & 0.041 & NA \\
Radiological outcomes nRCT & & & & & NA \\
PTSA (PC) & 12 & -1.72 & $(-2.139$ to -1.30$)$ & 0.001 & NA \\
CDI & 42 & 1.01 & $(0.55$ to 1.44$)$ & 0.001 & NA \\
\hline
\end{tabular}

Postoperative results were compared between the two groups in the lower half of the table

AX Anatomical axia, $P C$ posterior cortex, RCT randomized controlled trial, $n R C T$ non-randomized controlled trial, NA not available, HKA hip-knee-ankle angle, PTSA posterior tibial slope angle, CDI Caton-Deschamps Index, ISI Insall-Salvati Index, BPI Blackburne-Peel index

Table 6 Preoperative and postoperative imaging outcomes of each group after excluding the results of the follow-up within 1 year

\begin{tabular}{|c|}
\hline $\begin{array}{l}\text { Categories } \\
\text { and }\end{array}$ \\
\hline
\end{tabular}
and comparison Preoperative VS postoperative results in CWHTO

Radiological outcomes RCT

$\begin{array}{lllllll}\text { HKA } & 10,24,27,30 & -3.24 & (-3.64 \text { to }-2.86) & 0.001 & 82.7 & 0.003 \\ \text { PTSA(AX) } & 24 & 0.52 & (0.008 \text { to } 1.04) & 0.046 & \text { NA } & \text { NA } \\ \text { ISI } & 31 & -0.06 & (-0.63 \text { to } 0.51) & 0.84 & \text { NA }\end{array}$

Radiological outcomes nRCT

$\begin{array}{lllllll}\text { PTSA (PC) } & 12 & 0.92 & (0.54 \text { to } 1.29) & 0.003 & \text { NA } & \text { NA } \\ \text { CDI } & 42 & -0.21 & (-0.61 \text { to } 0.19) & 0.31 & \text { NA }\end{array}$

Preoperative VS postoperative results in OWHTO

Radiological outcomes RCT

\begin{tabular}{|c|c|c|c|c|c|c|}
\hline HKA & $10,24,27,30$ & -3.02 & $(-3.42$ to -2.63$)$ & 0.001 & 92.8 & 0.001 \\
\hline PTSA (AX) & 24 & -0.67 & $(-1.18$ to -0.15$)$ & 0.012 & NA & NA \\
\hline$|S|$ & 31 & 0.48 & (0.06 to 0.64$)$ & 0.06 & NA & NA \\
\hline \multicolumn{7}{|c|}{ adiological outcomes nRCT } \\
\hline PTSA (PC) & 12 & -0.58 & $(-0.94$ to -0.21$)$ & 0.002 & NA & NA \\
\hline CDI & 42 & 0.50 & (0.06 to 0.95$)$ & 0.026 & NA & NA \\
\hline
\end{tabular}

AX Anatomical axia, $P C$ posterior cortex, $R C T$ randomized controlled trial, $n R C T$ non-randomized controlled trial, NA not available, HKA hip-knee-ankle angle, $P T S A$ posterior tibial slope angle, CDI Caton-Deschamps Index, ISI Insall-Salvati Index, BPI Blackburne-Peel index 
height of the patellar tendon attachment site, thus causing a decrease in patellar height. This result occurs because CWHTO circumvents the drawbacks of OWHTO that the patellar height has not changed significantly. Tigani et al. [42] indicated that, according to the measurement of 40 knees after OWHTO, patellar lowering would become significant if the correction of the knee axis exceeded $15^{\circ}$. However, when the tibial tuberosity is left and attached to the proximal tibia [38], the patellar height can maintain unchanged after OWHTO, and the osteotomy site still has excellent blood perfusion due to the cancellous bone surface and is therefore very conducive to bone healing [42].

The main limitations of this systematic review and meta-analysis originate from the data pooled from the included articles. RCTs and nRCTs were both included when comparing OWHTO and CWHTO, especially having a greater caseload in the nRCTs, which may likely lead to bias. Nevertheless, the MINORS scores were acceptable when evaluating the quality of nRCTs, and the results of RCTs and nRCTs were processed respectively in order to reduce heterogeneity. Additionally, the follow-up periods and the internal fixation were diverse, which may affect the final results of the two surgical methods. In some subgroups, we did not find enough data, such as for ISI and BPI.

\section{Conclusion}

This meta-analysis indicates that compared with CWHTO, OWHTO increases the posterior slope, decreases the patellar height, and provides a similar accuracy of correction; however, CWHTO led to a deceased posterior slope and an unchanged patellar height. Therefore, programs should be personalized and customized for the specific situation of each patient.

\begin{abstract}
Abbreviations
AFTA: Anatomical femorotibial angle; AX: Anatomical axis; BPI: BlackburnePeel index; CDI: Caton-Deschamps index; HKA: Hip-knee-ankle angle; HSS: Hospital for Special Surgery Knee Score; ISI: Insall-Salvati Index; KSS: American Knee Society Score: MAD: Mechanical axis deviation: MMPTA: Mechanical medial proximal tibia angle; NA: Not available; nRCT: Non-randomized controlled trial; PC: Posterior cortex; PRISMA: Systematic Reviews and Meta-Analyses; PTSA: Posterior tibial slope angle; RCT: Randomized controlled trial; ROM: Range of motion; VAS: Visual Analog Scale Pain Score; WOMAC: The total of Western Ontario and McMaster University Osteoarthritis Index
\end{abstract}

\section{Publisher's Note}

Springer Nature remains neutral with regard to jurisdictional claims in publishedmaps and institutional affiliations.

\section{Authors' contributions}

XC extracted, analyzed, and interpreted the findings with guidance from AP or $\mathrm{FL}$ and wrote the preliminary manuscript and revised it based on advice from AP or FL. Review authors ( $F X$ and YH) provided comments to the preliminary manuscript and all subsequent versions. All review authors read and agreed on the current review version.

\section{Funding}

This study was funded by the China Scholarship Council (CSC) which supported four of the authors (Xiangyun Cheng, NO.: 201708140085; Fanxiao Liu, NO.: 201808080126; Fei Xiong, NO:: 201703920036 and Yijiang Huang, NO.: 201608330225)

Availability of data and materials

Data sharing is not applicable to this article as no datasets were generated or analyzed during the current study.

Ethics approval and consent to participate

Not applicable.

\section{Consent for publication}

Not applicable.

Competing interests

The authors declare that they have no competing interests.

Received: 12 November 2018 Accepted: 4 June 2019

Published online: 14 June 2019

\section{References}

1. Richmond J, Hunter D, Irrgang J, et al. American Academy of Orthopaedic Surgeons clinical practice guideline on the treatment of osteoarthritis (OA) of the knee. J Bone Joint Surg Am. 2010;92:990-3.

2. Ekhtiari S, Haldane CE, de Sa D, et al. Return to work and sport following high tibial osteotomy: a systematic review. J Bone Joint Surg Am. 2016;98: 1568-77.

3. Iorio R, Healy WL. Unicompartmental arthritis of the knee. J Bone Joint Surg Am. 2003:85-A:1351-64

4. Suero EM, Hawi N, Westphal R, et al. The effect of distal tibial rotation during high tibial osteotomy on the contact pressures in the knee and ankle joints. Knee Surg Sports Traumatol Arthrosc. 2017;25:299-305.

5. Petersen W, Metzlaff S. Open wedge high tibial osteotomy (HTO) versus mobile bearing unicondylar medial joint replacement: five years results. Arch Orthop Trauma Surg. 2016;136:983-9.

6. Takeuchi R, Umemoto Y, Aratake M, et al. A mid term comparison of open wedge high tibial osteotomy vs unicompartmental knee arthroplasty for medial compartment osteoarthritis of the knee. J Orthop Surg Res. 2010;5:65.

7. Santoso MB, Wu L. Unicompartmental knee arthroplasty, is it superior to high tibial osteotomy in treating unicompartmental osteoarthritis? A metaanalysis and systemic review. J Orthop Surg Res. 2017;12:50.

8. Park $\mathrm{CH}$, Bae DK, Kim Kl, et al. Serial changes in the joint space width and joint line convergence angle after closed-wedge high tibial osteotomy. Am J Sports Med. 2017:45:3254-61.

9. DeMeo PJ, Johnson EM, Chiang PP, et al. Midterm follow-up of openingwedge high tibial osteotomy. Am J Sports Med. 2010;38:2077-84.

10. Duivenvoorden T, Brouwer RW, Baan A, et al. Comparison of closing-wedge and opening-wedge high tibial osteotomy for medial compartment osteoarthritis of the knee: a randomized controlled trial with a six-year follow-up. J Bone Joint Surg Am. 2014;96:1425-32.

11. Brouwer RW, Bierma-Zeinstra SM, van Koeveringe AJ, et al. Patellar height and the inclination of the tibial plateau after high tibial osteotomy. The open versus the closed-wedge technique. J Bone Joint Surg Br. 2005;87: 1227-32.

12. El-Azab H, Halawa A, Anetzberger $\mathrm{H}$, et al. The effect of closed- and openwedge high tibial osteotomy on tibial slope: a retrospective radiological review of 120 cases. J Bone Joint Surg Br. 2008:90:1193-7.

13. Luites JW, Brinkman JM, Wymenga $A B$, et al. Fixation stability of openingversus closing-wedge high tibial osteotomy: a randomised clinical trial using radiostereometry. J Bone Joint Surg Br. 2009;91:1459-65. 
14. Smith TO, Sexton D, Mitchell $P$, et al. Opening- or closing-wedged high tibial osteotomy: a meta-analysis of clinical and radiological outcomes. Knee. 2011;18(6):361-8. doi: https://doi.org/10.1016/j.knee.2010.10.001.

15. Amzallag J, Pujol N, Maqdes A, et al. Patellar height modification after high tibial osteotomy by either medial opening-wedge or lateral closing-wedge osteotomies. Knee Surg Sports Traumatol Arthrosc. 2013;21:255-9.

16. Bae DK, Song SJ, Kim HJ, et al. Change in limb length after high tibial osteotomy using computer-assisted surgery: a comparative study of closedand open-wedge osteotomies. Knee Surg Sports Traumatol Arthrosc. 2013; 21:120-6.

17. Hankemeier S, Mommsen P, Krettek C, et al. Accuracy of high tibial osteotomy: comparison between open- and closed-wedge technique. Knee Surg Sports Traumatol Arthrosc. 2010;18:1328-33.

18. Ducat A, Sariali E, Lebel B, et al. Posterior tibial slope changes after opening and closing-wedge high tibial osteotomy: a comparative prospective multicenter study. Orthop Traumatol Surg Res. 2012;98:68-74.

19. Wu L, Lin J, Jin Z, et al. Comparison of clinical and radiological outcomes between opening-wedge and closing-wedge high tibial osteotomy: a comprehensive meta-analysis. PLoS One. 2017;12:e0171700.

20. Sun H, Zhou L, Li F, et al. Comparison between closing-wedge and opening wedge high tibial osteotomy in patients with medial knee osteoarthritis: a systematic review and meta-analysis. J Knee Surg. 2017;30:158-65.

21. Song $\mathbb{H}_{\text {, Song }} \mathrm{EK}$, Seo HY, et al. Patellofemoral alignment and anterior knee pain after closing- and opening-wedge valgus high tibial osteotomy. Arthroscopy. 2012;28:1087-93.

22. Portner O. High tibial valgus osteotomy: closing, opening or combined? Patellar height as a determining factor. Clin Orthop Relat Res. 2014;472:3432-40.

23. Polat G, Balci HI, Cakmak MF, et al. Long-term results and comparison of the three different high tibial osteotomy and fixation techniques in medial compartment arthrosis. J Orthop Surg Res. 2017;12:44.

24. Kim Jl, Kim BH, Lee KW, et al. Lower limb length discrepancy after high tibial osteotomy: prospective randomized controlled trial of lateral closing versus medial opening wedge osteotomy. Am J Sports Med. 2016;44:3095-102.

25. Duivenvoorden $T$, van Diggele $P$, Reijman $M$, et al. Adverse events and survival after closing- and opening-wedge high tibial osteotomy: a comparative study of 412 patients. Knee Surg Sports Traumatol Arthrosc. 2017;25:895-901.

26. Nerhus TK, Ekeland A, Solberg G, et al. Radiological outcomes in a randomized trial comparing opening wedge and closing wedge techniques of high tibial osteotomy. Knee Surg Sports Traumatol Arthrosc. 2017;25:910-7.

27. van Egmond N, van Grinsven S, van Loon CJ, et al. Better clinical results after closed-compared to open-wedge high tibial osteotomy in patients with medial knee osteoarthritis and varus leg alignment. Knee Surg Sports Traumatol Arthrosc. 2016;24:34-41.

28. Wingfield T, Tovar MA, Datta $\mathrm{S}$, et al. Addressing social determinants to end tuberculosis. Lancet. 2018;391:1129-32.

29. Zaugg V, Korb-Savoldelli V, Durieux $P$, et al. Providing physicians with feedback on medication adherence for people with chronic diseases taking long-term medication. Cochrane Database Syst Rev. 2018;(1):CD012042.

30. Gaasbeek RD, Nicolaas L, Rijnberg WJ, et al. Correction accuracy and collateral laxity in open versus closed wedge high tibial osteotomy. A oneyear randomised controlled study. Int Orthop. 2010;34:201-7.

31. Brouwer RW, Bierma-Zeinstra SM, van Raaij TM, et al. Osteotomy for medial compartment arthritis of the knee using a closing wedge or an opening wedge controlled by a Puddu plate. A one-year randomised, controlled study. J Bone Joint Surg Br. 2006;88:1454-9.

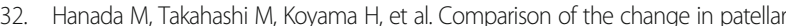
height between opening and closed wedge high tibial osteotomy: measurement with a new method. Eur J Orthop Surg Traumatol. 2014;24:567-70.

33. Deie M, Hoso T, Shimada N, et al. Differences between opening versus closing high tibial osteotomy on clinical outcomes and gait analysis. Knee. 2014:21:1046-51.

34. Tabrizi A, Soleimanpour J, Sadighi A, et al. A short term follow up comparison of genu varum corrective surgery using open and closed wedge high tibial osteotomy. Malays Orthop J. 2013;7:7-12.

35. Soleimanpour J, Elmi A, Jafari MA, et al. Comparison of genu varum treating results using open and closed wedge high tibial osteotomy. Pak J Biol Sci. 2013;16:686-91.

36. Bastos Filho R, Magnussen RA, Duthon V, et al. Total knee arthroplasty after high tibial osteotomy: a comparison of opening and closing wedge osteotomy. Int Orthop. 2013;37:427-31.
37. Magnussen RA, Lustig S, Demey G, et al. The effect of medial opening and lateral closing high tibial osteotomy on leg length. Am J Sports Med. 2011;39:1900-5.

38. El-Azab H, Glabgly P, Paul J, et al. Patellar height and posterior tibial slope after open- and closed-wedge high tibial osteotomy: a radiological study on 100 patients. Am J Sports Med. 2010;38:323-9.

39. van Raaij TM, Brouwer RW, de Vlieger R, et al. Opposite cortical fracture in high tibial osteotomy: lateral closing compared to the medial openingwedge technique. Acta Orthop. 2008;79:508-14.

40. Schaefer TK, Majewski M, Hirschmann MT, et al. Comparison of sagittal and frontal plane alignment after open- and closed-wedge osteotomy: a matched-pair analysis. J Int Med Res. 2008:36:1085-93.

41. Hoell S, Suttmoeller J, Stoll V, et al. The high tibial osteotomy, open versus closed wedge, a comparison of methods in 108 patients. Arch Orthop Trauma Surg. 2005;125:638-43.

42. Tigani $D$, Ferrari $D$, Trentani $P$, et al. Patellar height after high tibial osteotomy. International Orthopaedics. 2001;24:331-4.

43. Robin JG, Neyret P. High tibial osteotomy in knee laxities: concepts review and results. EFORT Open Rev. 2016;1:3-11.

44. Agneskirchner JD, Hurschler C, Stukenborg-Colsman C, et al. Effect of high tibial flexion osteotomy on cartilage pressure and joint kinematics: a biomechanical study in human cadaveric knees. Winner of the AGA-DonJoy Award 2004. Arch Orthop Trauma Surg. 2004;124:575-84.

45. Wight $L$, James $D$. Intra-articular patellar dislocation: a technique for closed reduction: a case report and review of the literature. JBJS Case Connect. 2017;7:e94.

46. Loia MC, Vanni S, Rosso F, et al. High tibial osteotomy in varus knees: indications and limits. Joints. 2016;4:98-110.

47. Berman AT, Bosacco SJ, Kirshner S, et al. Factors influencing long-term results in high tibial osteotomy. Clin Orthop Relat Res. 1991:192-8.

48. Schroter S, Mueller J, van Heerwaarden R, et al. Return to work and clinical outcome after open wedge HTO. Knee Surg Sports Traumatol Arthrosc. 2013;21:213-9.

49. Kim MS, Koh IJ, Choi YJ, et al. Collagen augmentation improves the quality of cartilage repair after microfracture in patients undergoing high tibial osteotomy: a randomized controlled trial. Am J Sports Med. 2017:45:1845-55.

50. Aglietti P, Buzzi R, Vena LM, et al. High tibial valgus osteotomy for medial gonarthrosis: a 10- to 21-year study. J Knee Surg. 2003;16:21-6.

51. Takeuchi R, Ishikawa H, Miyasaka Y, et al. A novel closed-wedge high tibial osteotomy procedure to treat osteoarthritis of the knee: hybrid technique and rehabilitation measures. Arthrosc Tech. 2014;3:e431-7.

52. Reising K, Strohm PC, Hauschild O, et al. Computer-assisted navigation for the intraoperative assessment of lower limb alignment in high tibial osteotomy can avoid outliers compared with the conventional technique. Knee Surg Sports Traumatol Arthrosc. 2013:21:181-8.

53. Goleski P, Warkentine B, Lo D, et al. Reliability of navigated lower limb alignment in high tibial osteotomies. Am J Sports Med. 2008;36:2179-86.

54. Ozcan O, Eroglu M, Boya $\mathrm{H}$, et al. Proximal tibiofibular joint pain versus peroneal nerve dysfunction: clinical results of closed-wedge high tibial osteotomy performed with proximal tibiofibular joint disruption. Knee Surg Sports Traumatol Arthrosc. 2017:25:2936-41.

55. Giffin JR, Vogrin TM, Zantop T, et al. Effects of increasing tibial slope on the biomechanics of the knee. Am J Sports Med. 2004;32:376-82.

56. Niinimaki TT, Eskelinen A, Mann BS, et al. Survivorship of high tibial osteotomy in the treatment of osteoarthritis of the knee: Finnish registrybased study of 3195 knees. J Bone Joint Surg Br. 2012;94:1517-21.

\section{Ready to submit your research? Choose BMC and benefit from:}

- fast, convenient online submission

- thorough peer review by experienced researchers in your field

- rapid publication on acceptance

- support for research data, including large and complex data types

- gold Open Access which fosters wider collaboration and increased citations

- maximum visibility for your research: over $100 \mathrm{M}$ website views per year

At $\mathrm{BMC}$, research is always in progress.

Learn more biomedcentral.com/submissions 